\title{
Moeda, títulos e financiamento do Tesouro no Brasil: um exemplo numérico*
}

\author{
Currency, bonds and Treasury financing in Brazil: a numerical example
}

\author{
Nelson Henrique Barbosa Filho**
}

\begin{abstract}
Resumo: Este artigo apresenta um exemplo teórico e numérico do financiamento direto e indireto de déficit público pelo Banco Central na economia brasileira, incluindo seus efeitos nas reservas compulsórias dos bancos. O principal resultado é que, dada a demanda por liquidez à taxa de juro definida pelo Banco Central, financiamento direto ou indireto da dívida pública têm o mesmo efeito. Somente com taxa básica de juro zero as duas alternativas diferem.
\end{abstract}

Palavras-chave: Moeda; Dívida Pública; Economia Brasileira

\begin{abstract}
This paper presents a theoretical and numerical example of direct an indirect financing of budget deficits by the Central Bank in the Brazilian economy, including its effects on compulsory banks' reserves. The main result is that, given the demand for liquidity at the base interest rate set by the Central Bank, direct and indirect financing of public debt have the same result. Only at a zero-base interest rate the two alternatives differ.
\end{abstract}

Keywords: Money; Public Debt; Brazilian Economy

JEL Code: E58; H63; N16

\footnotetext{
* Submissão: 06/05/2020; aprovação: 28/06/2020. DOI: 10.5380/re.v41i75.74011.

** Professor da Escola de Economia de São Paulo da Fundação Getúlio Vargas (EESP/FGV) e da Universidade de Brasília (UnB). Pesquisador do Instituto Brasileiro de Economia da Fundação Getúlio Vargas (IBRE/FGV). E-mail: nelson.barbosa@fgv.br. O autor agradece os comentários e sugestões de Ricardo Carneiro e Guilherme Mello. Eventuais erros e omissões são de responsabilidade do autor.
} 


\section{Introdução}

A crise do Covid-19 gerou debate sobre a relação entre Banco Central (BC) e Tesouro Nacional (TN) no Brasil. Diante do aumento necessário da dívida pública, vários economistas apontaram que o $\mathrm{BC}$ deveria financiar diretamente o TN, com emissão direta para a autoridade monetária (BOLLE et al., 2020). Este texto apresenta considerações sobre o financiamento direto e indireto do déficit público, usando um exemplo numérico simplificado das variações dos balancetes dos principais agentes institucionais envolvidos no processo.

Para simplificar a exposição, assumirei que: (i) a base monetária consiste somente de reservas bancárias; (ii) somente os bancos comerciais financiam o TN (ou seja, não há Tesouro Direto); e (iii) a contrapartida da emissão de títulos do TN é o aumento do "valor presente dos resultados fiscais esperados para o futuro".

Sobre a hipótese (iii), em termos contábeis, a emissão de título reduz o patrimônio líquido do TN, que por definição é igual ao simétrico do valor presente da expectativa de superávits fiscais futuros, na "contabilidade intertemporal de expectativas" adotada por economistas (WALSH, 2018).

\section{Financiamento direto versus indireto}

O financiamento direto do TN pelo BC é proibido no Brasil. O BC pode comprar títulos públicos no mercado, mas não diretamente do TN para separar administração de liquidez de cobertura de desequilíbrio orçamentário. Mas o que aconteceria se isto fosse permitido? Vale apena ilustrar a mecânica do financiamento direto com um exemplo numérico.

Assuma-se que o TN tem necessidade de liquidez de \$10 para fazer transferências de renda, ou seja depósitos nas contas do setor não bancário. Os lançamentos nos balancetes dos agentes envolvidos ocorrem da seguinte forma:

1) BC compra $\$ 10$ de títulos do TN (+10 na conta única e nos títulos do BC).

2) TN gasta os $\$ 10$ captados junto aos bancos (-10 na conta única, +10 na base monetária, +10 nos depósitos à vista de quem recebeu do $\mathrm{TN})$.

3) Assumindo compulsório de $20 \%$, bancos têm que depositar $\$ 2$ no BC devido à expansão dos depósitos à vista ( -2 na base monetária, +2 no compulsório). 
4) Até aqui a base monetária subiu $\$ 8$. Se a demanda por liquidez continua a mesma, o BC terá que restaurar a base ao valor inicial para evitar que a SELIC caia. O BC precisa tirar a liquidez excedente do sistema.

5) BC vende títulos para enxugar $\$ 8$ (-8 na base monetária, -8 nos títulos na carteira do $\mathrm{BC},+8$ nos títulos dos bancos).

No final do processo, a dívida do TN subiu em $\$ 10$, sendo $\$ 8$ com os bancos e \$2 com o BC. Já nos bancos, os depósitos à vista aumentaram em \$10, tendo como contrapartida mais $\$ 8$ em títulos e $\$ 2$ em compulsório. A tabela 1 apresenta a sequência acima no balancete dos agentes envolvidos.

Tabela 1 - Exemplo numérico de financiamento direto do Tesouro Nacional pelo Banco Central

\begin{tabular}{|c|c|c|c|c|c|}
\hline & $\begin{array}{c}\text { BC compra } \\
\text { títulos } \\
\text { diretamente } \\
\text { do } T N\end{array}$ & $\begin{array}{l}\text { TN paga o } \\
\text { setor não } \\
\text { bancário }\end{array}$ & $\begin{array}{c}\text { Bancos } \\
\text { depositam } \\
20 \% \text { do DV } \\
\text { no BC como } \\
\text { compulsório }\end{array}$ & $\begin{array}{c}\text { BC restaura } \\
\text { base } \\
\text { monetária } \\
\text { ao valor } \\
\text { original }\end{array}$ & $\begin{array}{l}\text { Variação } \\
\text { total }\end{array}$ \\
\hline \multicolumn{6}{|l|}{ Balanço do BC } \\
\hline Títulos públicos no BC & 10 & & & -8 & 2 \\
\hline Base monetária & & -10 & 2 & 8 & 0 \\
\hline Compulsório & & & -2 & & -2 \\
\hline Conta Única & -10 & 10 & & & 0 \\
\hline \multicolumn{6}{|l|}{ Balanço do Tesouro } \\
\hline Conta Única & 10 & -10 & & & 0 \\
\hline VP do Res Futuro & & 10 & & & 10 \\
\hline Títulos públicos no BC & -10 & & & 8 & -2 \\
\hline $\begin{array}{l}\text { Títulos públicos nos } \\
\text { Bancos }\end{array}$ & & & & -8 & -8 \\
\hline \multicolumn{6}{|l|}{ Balanço do Bancos } \\
\hline Base monetária & & 10 & -2 & -8 & 0 \\
\hline Compulsório & & & 2 & & 2 \\
\hline $\begin{array}{l}\text { Títulos públicos nos } \\
\text { Bancos }\end{array}$ & & & & 8 & 8 \\
\hline $\begin{array}{l}\text { Bancos } \\
\text { Depósito à vista }\end{array}$ & & -10 & & & -10 \\
\hline \multicolumn{6}{|l|}{ Balanço do Público } \\
\hline Depósito à vista & & 10 & & & 10 \\
\hline PL do público & & -10 & & & -10 \\
\hline
\end{tabular}

Fonte: elaboração do autor.

Obs: (+) representa crédito e (-) débito. 
Agora vejamos o caso de financiamento indireto do TN pelo $\mathrm{BC}$, baseado no que já é permitido pela legislação brasileira:

1) TN emite $\$ 10$ em títulos para os bancos (+10 na conta única, -10 na base monetária, +10 nos títulos dos bancos).

2) TN gasta os $\$ 10$ captados com o setor não bancário (-10 na conta única, +10 na base monetária, +10 nos depósitos à vista).

3) Assumindo compulsório de 20\%, bancos tem que depositar $\$ 2$ no BC devido à expansão dos depósitos à vista (-2 base monetária, +2 compulsório).

4) Até aqui a base monetária caiu $\$ 2$. Se a demanda continua a mesma, o $\mathrm{BC}$ terá que restaurar a base ao valor inicial para evitar que a SELIC suba. O BC tem que injetar liquidez no sistema.

5) $\mathrm{BC}$ compra títulos para injetar $\$ 2$ no sistema (+2 na base, +2 títulos livres na carteira do $\mathrm{BC},-2$ títulos na carteira dos bancos).

O resultado é o mesmo do caso anterior, isto é, a dívida do TN subiu em $\$ 10$, sendo $\$ 8$ com o público e $\$ 2$ com o $\mathrm{BC}$. Nos bancos, os depósitos à vista aumentaram em $\$ 10$, tendo como contrapartida $\$ 8$ em títulos e $\$ 2$ em compulsório. A tabela 2 descreve os passos. 
Tabela 2 - Exemplo numérico de financiamento indireto do Tesouro Nacional pelo Banco Central

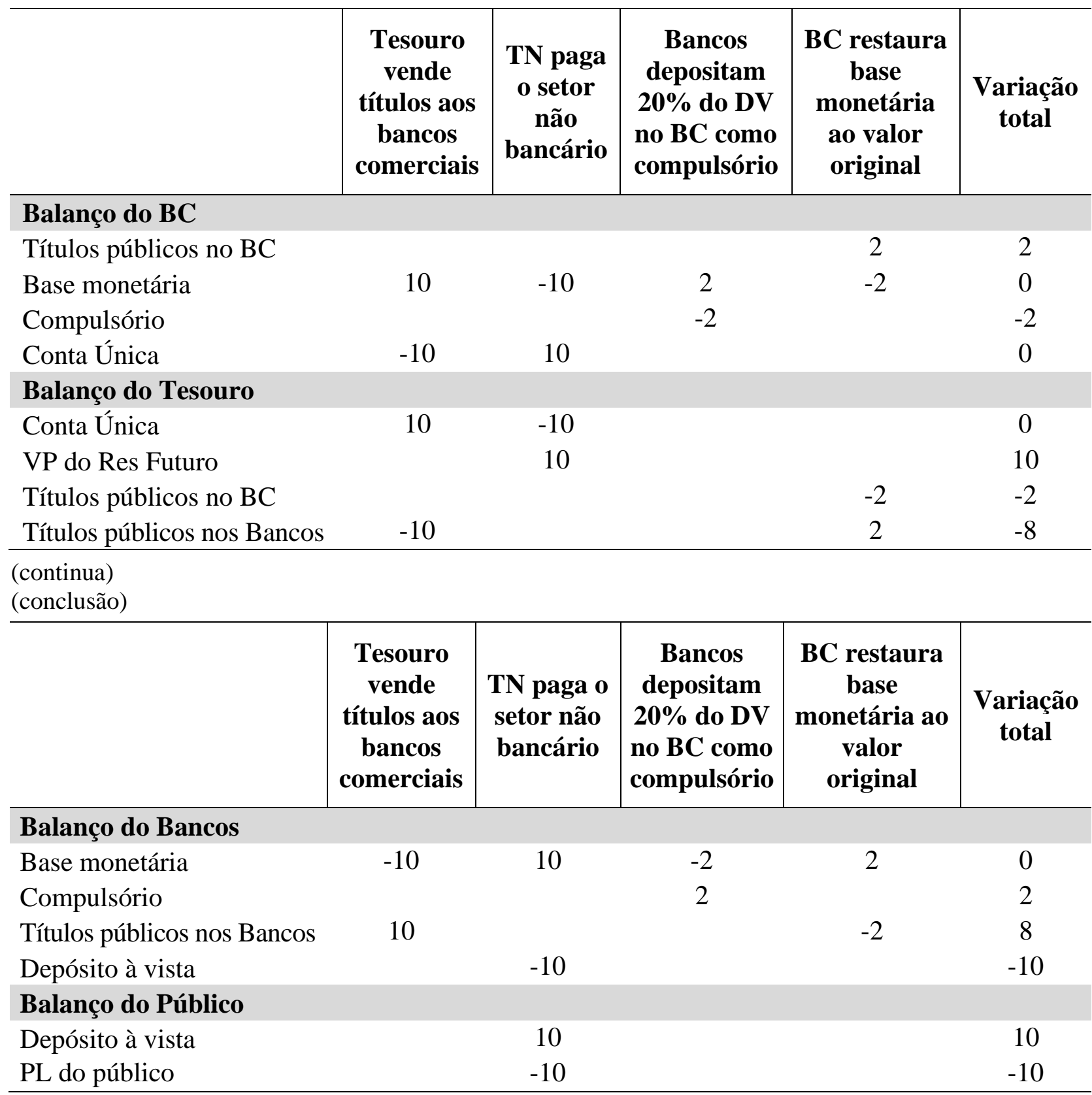

Fonte: elaboração do autor.

Obs: (+) representa crédito e (-) débito

\section{Considerações finais}

Assumindo que a demanda por liquidez seja constante a SELIC determinada pelo $\mathrm{BC}$, a principal diferença entre os dois casos analisados acima é que, no financiamento direto a base monetária sobe e depois cai, enquanto no financiamento indireto a base cai e depois sobe. 
Nos dois casos analisados o ponto crucial é a hipótese de que a demanda por base monetária não se alterou, tornando necessário enxugar liquidez no caso de financiamento direto ou injetar liquidez no caso de financiamento indireto. Em outras palavras, nos dois casos, mantida a SELIC necessária para controlar a inflação, a demanda por base monetária é a mesma.

Mas e se a SELIC cair? Neste caso a demanda por liquidez do sistema pode subir, fazendo com que o $\mathrm{BC}$ não tenha que esterilizar em $100 \%$ o financiamento do déficit. Seja via financiamento direto ou indireto, com redução da SELIC a base monetária pode subir e absorver parte da emissão de dívida pelo TN. Por exemplo, o resultado de mais $\$ 10$ de dívida pode ser mais $\$ 2$ de compulsório, mais $\$ 3$ de moeda e mais $\$ 5$ de títulos nos bancos.

E mesmo com a SELIC constante, se a ação do TN aumentar o PIB, a demanda por moeda pode subir e permitir que parte da emissão de dívida seja absorvida com elevação da base monetária. Neste caso o impacto depende da eficácia da ação fiscal do TN, que é motivo de grande debate, mas que foge ao escopo deste breve texto.

Por fim, e se a SELIC for zero? No caso de financiamento direto não haverá necessidade de enxugar liquidez (passo 5 acima). Os $\$ 10$ de dívida seriam absorvidos como $\$ 8$ em moeda e $\$ 2$ em compulsório.

Já no caso de financiamento indireto, mesmo com SELIC zero, o BC teria que injetar liquidez no sistema (passo 5 acima) para evitar que a SELIC subisse. Os $\$ 10$ de dívida seriam financiados, portanto, via $\$ 8$ em títulos dos bancos e $\$ 2$ em compulsório.

A principal conclusão dos exercícios numéricos acima é que o debate sobre financiamento direto ou indireto do BC é mais relevante no contexto de SELIC zero. Como o Brasil ainda não chegou a tal situação, nosso principal debate monetário no continua sendo até onde o BC pode reduzir a SELIC nesta crise. A resposta depende do cenário para inflação, câmbio e atividade econômica, que fogem do escopo deste texto.

\section{Referências}

BOLLE, M. B. de; CARVALHO, A. R. de; TERRA, F. H. B.; GALÍPOLO, G.; ROCHA, I.; BRAGA, J.; BELLUZZO, L. G. de M. Emitindo moeda o Estado cria poder de compra que antes não existia. Folha de São Paulo, 30 abr. 2020. 
WALSH, C. E. Monetary Economics: Theory and Policy. Cambridge: The MIT Press, 2017. 